\title{
ANÁLISE CRÍTICA DOS ACIDENTES DE TRABALHO NO BRASIL
}

\author{
CRITICAL ANALYSIS OF ACCIDENTS AT WORK IN BRAZIL
}

\author{
Cleonice Andréa Alves Cavalcante ${ }^{\mathrm{a}^{*}}$, Marcelly Santos Cossi ${ }^{\mathrm{b}^{*}}$, Raphael Raniere de Oliveira \\ Costa $^{\mathrm{c}^{*}}$, Soraya Maria de Medeiros ${ }^{\mathrm{d}^{*}}$, Rejane Maria Paiva de Menezes ${ }^{\mathrm{e}^{*}}$ \\ acleoandreaeen@gmail.com, ${ }^{b}$ marcellycossi@gmail.com, craphaelraniere@hotmail.com, \\ dsorayamaria_ufrn@hotmail.com, erejemene@terra.com.br \\ *Universidade Federal do Rio Grande do Norte - Natal (RN), Brasil
}

Data de entrada do artigo: 05/04/2014 Data de aceite do artigo: 05/01/2015

\section{RESUMO}

Introduçáo: No Brasil, o acidente de trabalho é considerado um importante problema de saúde pública, pois além de causar prejuízos aos trabalhadores e empregadores, afeta a economia do país e, portanto, merece uma análise dos seus aspectos para uma melhor compreensáo e controle dos riscos. Objetivo: Descrever e discutir os aspectos relacionados aos acidentes de trabalho no Brasil a partir de uma análise crítica e reflexiva. Metodologia: Revisão narrativa que permite uma análise qualitativa da literatura sob o ponto de vista teórico ou contextual. Utilizamos o referencial teórico de Hinds, Chaves e Cypress, que caracteriza o contexto em quatro camadas interativas - imediato, específico, geral e metacontexto -, que se distinguem entre si e vão desde o significado totalmente individualizado ao significado universal. Resultados: O Acidente de trabalho foi analisado na perspectiva de suas características, classificação e epidemiologia; seus principais problemas, dificuldades e limitaçóes no contexto brasileiro; suas consequências e sequelas na vida do trabalhador vitimado, além do seu caráter histórico, institucional e jurídico. Conclusáo: $\mathrm{O}$ entendimento dos contextos contribui no processo de planejamento, organização e intervençôes da enfermagem do trabalho no referido campo de atuação.

Palavras chaves: Acidentes de trabalho; saúde do trabalhador; enfermagem do trabalho.

\section{ABSTRACT}

Introduction: In Brazil, accidents at work are considered an important public health problem since it causes harm to workers and employers and affects the country's economy. Therefore, it deserves an analysis of their aspects for a better understanding and control of risks. Objective: to describe and discuss the aspects of work-related accidents in Brazil from a critical and reflective analysis. Methodology: Narrative review which allows a qualitative analysis of the literature on a particular topic under a contextual or theoretical point of view. We use the theoretical framework of Hinds, Chaves and Cypress that characterizes the environment in four layers - immediate, interactive and metacontexto -, distinguished among themselves and ranging from the totally individualized meaning to the universal meaning. Results: accidents at work were analyzed in terms of their characteristics, classification and epidemiology; their main problems, difficulties and limitations in the Brazilian context; its consequences and after-effects in the life of victimized workers, in addition to its historical, institutional and legal character. Conclusion: understanding the contexts helps in the planning process, organization and nursing interventions at work in that field.

Keywords: Work accidents; occupational health; occupational health nursing. 


\section{Introdução}

Historicamente os trabalhadores têm sofrido diversas mazelas no meio ambiente de trabalho, com grandes repercussōes nos âmbitos psicossocial, econômico e da saúde. Sua exposiçấo a riscos físicos, químicos, ergonômicos, psicossociais e/ou biológicos advindos da execução do trabalho pode resultar em doenças e agravos ocupacionais. ${ }^{1}$ A doença profissional é definida como qualquer doença "produzida ou desencadeada pelo exercício do trabalho peculiar à determinada atividade" [p. $\mathrm{x}$ x]. Já os agravos relacionados com o trabalho são constituídos pelas doenças e acidentes que acometem a populaçâo em geral, mas que adquirem características particularmente diferenciadas em certas categorias. ${ }^{2}$

Conforme a Lei Orgânica do Sistema Único de Saúde (SUS) nº 8.080/90, as açốes de saúde devem garantir condições de bem-estar físico, mental e social às pessoas e à coletividade, incluindo políticas econômicas e sociais que possibilitem o acesso universal e igualitário da população a serviços para promoção, proteçấo e recuperação da saúde. ${ }^{3}$ No âmbito deste direito, um dos eixos importantes é a Saúde do Trabalhador, subárea voltada às relaçóes entre trabalho e saúde.

Com a Política Nacional de Saúde do Trabalhador do Ministério da Saúde (MS), pretende-se reduzir os acidentes e doenças relacionadas ao trabalho através de ações de promoção, reabilitação e vigilância na área da saúde $e^{4}$ Sua principal estratégia é a Rede Nacional de Atençáo Integral à Saúde do Trabalhador (RENAST), composta pelos Centros Estaduais e Regionais de Referência em Saúde do Trabalhador (CERESTs) - polos de suporte técnico e científico no processo de trabalho/saúde/doença, que desenvolvem ações de prevenção e vigilância para melhoria das condiçóes de trabalho e qualidade de vida dos trabalhadores -, e por redes sentinelas de serviços médicos e ambulatoriais de média e alta complexidade, responsáveis por diagnosticar acidentes e doenças relacionados ao trabalho e registrá-los no Sistema de Informação de Agravos de Notificação (Sinan-net), um sistema desenvolvido para a coleta e divulgação dos dados gerados rotineiramente na vigilância epidemiológica. ${ }^{4}$

Entre os agravos relacionados ao trabalho, o acidente de trabalho (AT) é considerado o mais grave e, portanto, o de maior importância epidemiológica devido a sua elevada ocorrência no Brasil, representando aproximadamente $25 \%$ das lesóes por causas externas atendidas em serviços de emergência. ${ }^{5}$

No Brasil, o acidente de trabalho é considerado um importante problema de saúde pública, pois além de causar prejuízos aos trabalhadores e empregadores, afeta a economia do país e, portanto, merece uma análise dos seus aspectos para uma melhor compreensão e controle dos riscos. No entanto, o conhecimento da magnitude do problema ainda é bastante limitado, pois apesar da existência de um aparato legal no país para que os acidentes de trabalho sejam notificados e a informação produzida norteie as açôes na promoção e na prevenção de danos à saúde dos trabalhadores, a subnotificação é uma realidade que dificulta o conhecimento das reais condiçôes em que o trabalho se desenvolve, desqualificando os direitos sociais e securitários ao trabalhador. ${ }^{6,7}$

O desconhecimento do fenômeno, de seus determinantes e da distribuição de sua ocorrência em determinado território impede ou dificulta uma análise adequada dos fatores potenciais que estão em sua origem, prejudicando o alcance das açôes preventivas. Além disso, o modelo de atenção à saúde de caráter curativista dificulta o reconhecimento dos condicionantes do processo de adoecimento no trabalho e de riscos mais complexos dessa relaçấo que permitam o desenvolvimento de ações de promoção à saúde no trabalho, e a proposição de um contexto de trabalho decente. ${ }^{8}$

Além disso, as doenças e agravos relacionadas ao trabalho encontram problemas para serem reconhecidos como vinculados ao trabalho, sobretudo na atualidade, considerando a globalização e a flexibilização da economia que têm se refletido nas perdas dos direitos trabalhistas e na degradaçáo do trabalho e da saúde. Na realidade, o reconhecimento do problema como originário do e pelo trabalho, isto é, o nexo causal, tem se constituído em um verdadeiro calvário para os trabalhadores que vão e vêm em busca de diagnóstico e vínculo do seu problema de saúde ao seu trabalho. ${ }^{9}$

O estudo sobre os acidentes de trabalho no Brasil tem se mostrado de importância fundamental no cenário das atividades de vigilância em saúde, pois permite a realização do diagnóstico da ocorrência do evento na população, fornecendo subsídios para explicações causais dos agravos de notificação compulsória, além de indicar os riscos aos quais os trabalhadores estão submetidos, contribuindo assim para a identificação da realidade epidemiológica. Portanto, é um instrumento relevante para auxiliar o planejamento da saúde, definir prioridades de intervenção, além de permitir que seja avaliado o impacto das intervenções.

No contexto da Vigilância à Saúde do Trabalhador, o Ministério da Saúde reconhece como atribuiçấo do profissional enfermeiro, como elemento da equipe de Saúde uma atuação contínua e sistemática, no sentido de detectar, conhecer, pesquisar e analisar os fatores determinantes e condicionantes dos agravos à saúde relacionados aos processos e ambientes de trabalho em seus aspectos tecnológico, social, organizacional e epidemiológico, com o objetivo de planejar, executar e avaliar intervençóes sobre eles de forma a eliminá-los ou controlá-los. 
Considerando a magnitude da temática, objetivou-se neste estudo descrever e discutir os aspectos relacionados aos acidentes de trabalho no Brasil a partir de uma análise crítica e reflexiva sob o ponto de vista contextual.

Para tanto, utilizamos o referencial teórico de Hinds, Chaves e Cypress ${ }^{10}$ que caracteriza o contexto em quatro camadas interativas - o imediato, o específico, o geral e o metacontexto -, que se distinguem entre si e vão desde o significado totalmente individualizado ao significado universal, na qual a interação proposital do pesquisador com o contexto aumenta a exatidáo e a perfeição das interpretaçóes, amplia o valor explicativo dos resultados, cria condiçóes para a compreensão dos processos da vida humana e permite o compartilhar do seu significado e de sua compreensão.

\section{Metodologia}

Trata-se de uma revisão narrativa que permite uma análise qualitativa da literatura sobre determinado assunto sob o ponto de vista teórico ou contextual.

Constitui-se de uma análise da literatura publicada em artigos de revistas impressas e/ou eletrônicas com interpretação e análise crítica pessoais do autor. Sua metodologia permite ao leitor uma atualização sobre uma determinada temática, porém não admite a reprodução dos dados e nem fornece respostas quantitativas para questóes específicas. ${ }^{11}$

As fontes bibliográficas pesquisadas para a temática deste estudo foram as publicaçôes impressas em livros e documentos de organismos oficiais, como a Organização Internacional do Trabalho, Ministério da Saúde, Ministério da Previdência Social, o Ministério do Trabalho e Emprego e a FUNDACENTRO, bem como pesquisas online registradas nas bases de informaçôes do Scientific Eletronic Library Online (SciELO), do Centro Latino-Americano e do Caribe de Informação em Ciências da Saúde (Bireme) e da Literatura Latino-Americana e do Caribe em Ciências da Saúde (LILACS). Realizamos também uma busca na base de informação da Web of Science, no período dos últimos cinco anos, de estudos que substanciassem os achados obtidos nas fontes do Scielo e Bireme.

A busca foi realizada entre os meses de julho e agosto de 2013. Os critérios de inclusão foram: publicaçóes dos últimos 5 anos que abordassem a temática dos acidentes de trabalho, tendo como critério de exclusão data de publicação anterior a 2008 e a não abordagem da temática aqui estudada. Após a leitura exaustiva do material selecionado, foram analisados 29 artigos.

O material bibliográfico foi selecionado a partir da leitura integral do texto ou de seu resumo e adequação ao objetivo proposto. Em seguida, analisamos os diferentes contextos da temática à luz do referencial teórico de modo que os estudos encontrados fossem integrados em subtemas, conforme a perspectiva conceitual de cada contexto.

O contexto é uma fonte de dados, significados e compreensão do fenômeno que diz respeito ao entendimento do modo como esse fenômeno está inserido nas suas camadas. Somente através das interaçôes propositais com as camadas do contexto, poderão os profissionais de saúde predizer, explicar e controlar o efeito de seus cuidados, o que resultará em um significado completo e sistemático dos fenômenos humanos. A incorporação do contexto em um estudo pode enriquecer e ampliar seu resultado e conclusóes, providenciando uma base para a aplicação clínica dos seus resultados. ${ }^{10}$

A partir das características de cada contexto proposto pelo referencial teórico, o artigo foi categorizado em quatro subtemas, a saber: Acidentes de trabalho: características, classificação e epidemiologia; Acidentes de trabalho: problemas, dificuldades e limitaçóes; Acidentes de trabalho: consequências e sequelas; e Acidentes de trabalho: o passado, o presente e o futuro.

\section{Resultados e discussão}

\section{Acidentes de trabalho: classificação, características e epidemiologia}

De acordo com a Organização Internacional do Trabalho (OIT), acidente do trabalho é todo acontecimento inesperado e imprevisto, incluindo atos de violência, derivado do trabalho ou com ele relacionado, do qual resulta uma lesão corporal, uma doença ou a morte de um ou vários trabalhadores. ${ }^{12}$

O acidente de trabalho é entendido como um evento imprevisível que acontece no exercício do trabalho e que traz como consequência uma lesão corporal ou perturbação funcional, com perda ou redução da capacidade para o trabalho, de forma permanente ou temporária, ou até mesmo a morte. ${ }^{4} \mathrm{~A}$ legislação previdenciária considera também como acidente de trabalho a doença que ocorre em decorrência da atividade profissional..$^{13}$

No Brasil, o AT é definido como o evento ocorrido no exercício da atividade laboral, independentemente da situação empregatícia e previdenciária do acidentado, e que acarreta dano potencial ou imediato à saúde, provocando lesão corporal ou perturbação funcional que causa, direta ou indiretamente, a morte, a perda ou a redução, permanente ou temporária, da capacidade para o trabalho. Inclui o ocorrido em situaçáo em que o trabalhador esteja representando os interesses da 
empresa ou agindo em defesa de seu patrimônio; assim como o ocorrido no trajeto da residência para o trabalho ou vice-versa. ${ }^{14}$

Esses acidentes são classificados ainda em acidente do trabalho fatal aquele que leva ao óbito imediatamente após sua ocorrência, ou aquele em que o óbito que venha a ocorrer posteriormente, a qualquer momento, em ambiente hospitalar ou não, desde que a causa básica, intermediária ou imediata da morte seja decorrente do acidente. $\mathrm{O}$ acidente do trabalho mutilante (grave) é aquele que acarreta mutilação, física ou funcional, e o que leva à lesão cuja natureza implique comprometimento extremamente sério, preocupante e que posse ter consequências nocivas ou fatais. ${ }^{15}$

Classifica-se ainda como acidente de trabalho típico (ATT) aquele que ocorre durante o desempenho laboral, como acidente de trajeto o que se dá durante o deslocamento entre a residência e o local de trabalho, como doença profissional aquela que foi produzida ou desencadeada pelo exercício do trabalho inerente à atividade, e como doença do trabalho a adquirida ou desencadeada por condiçóes especiais em que o trabalho é realizado e que com ele se relacione. ${ }^{16}$

No Brasil, a problemática do ATT encontra-se relacionada ao processo de trabalho a partir do momento em que as transformaçóes ocorridas no processo produtivo ampliam os espaços de exercício profissional, expandido-os para as ruas. Desse modo, representou também novas exposições a riscos ou intensificação de exposiçóes já existentes. ${ }^{17} \mathrm{O}$ estudo de Miranda et al ${ }^{18}$ constatou que o espaço da rua e o contato direto com o público permanecem como fatores de risco de acidentes de trânsito e violência em geral. Com relação aos óbitos causados pelo trabalho, percebe-se que a violência urbana ganha relevância como fator desencadeante.

Para se entender a dimensão que assumiu o acidente de trajeto no Brasil ao longo dos anos, o estudo de Lourenço ${ }^{9}$ analisou os acidentes e doenças relacionados ao trabalho ocorridos e registrados no período de 1970 a 2009, e evidenciou que os acidentes de trajeto apresentaram aumento exponencial a cada ano, saltando de 14.502 casos, em 1970, para 89.445, em 2009; enquanto o acidente típico apresentou uma diminuiçáo de 1.199.672 em 1970 para 421.141 em 2009. Contudo a letalidade em relação ao total de agravos dobrou durante o período analisado caracterizando que os acidentes a despeito da mudança de cenário continua vitimando os trabalhadores no Brasil. No entanto, a autora salienta que nos 25 anos contemplados pelo estudo, mais de 29 milhóes de acidentes e mais de cem mil mortes relacionadas ao trabalho foram registradas no Brasil, mas é preciso considerar que parcela considerável dos trabalhadores que compóe o setor informal da economia náo foi considerada.
Em relação aos riscos específicos, os acidentes de trabalho são prejudiciais à saúde dos trabalhadores em decorrências dos riscos da atividade laboral, das condiçóes ambientais onde o trabalho é realizado, das características físicas e psíquicas do trabalhador do contexto social, econômico e político. Sáo causados pela ruptura da relação entre saúde e trabalho, interferindo no processo saúde/doença do trabalhador de maneira abrupta ou insidiosa, com repercussóes pessoais, econômicas e sociais. ${ }^{19}$

Os acidentes de trabalho ainda representam a maioria dos casos do Auxílio-Doença no Brasil, o que aponta para a persistência da precariedade das medidas de segurança nos ambientes do trabalho. Esse custo é assumido pelo Ministério da Previdência Social por meio do Instituto Nacional de Seguridade Social (INSS) que assume parte dos custos diretos com ATs cujas contribuições destinam-se ao custeio de despesas com vários benefícios. Diferentemente em países desenvolvidos as doenças do trabalho representam a maioria dos casos de incapacidade de natureza acidentária. Assim, é extremamente difícil vislumbrar que em um futuro próximo o Brasil consiga prevenir de forma efetiva as doenças do trabalho, uma vez que, até o momento, não conseguiu superar as elevadas taxas de acidentes de origem traumática. ${ }^{20}$

Segundo a Organização Internacional do Trabalho (OIT), ocorrem anualmente cerca de 270 milhóes de acidentes de trabalho no mundo, dos quais 2 milhóes seriam fatais, e aproximadamente 6.000 trabalhadores morrem a cada dia devido a acidentes e doenças relacionadas com o trabalho. Além disso, a cada ano ocorrem 270 milhões de acidentes do trabalho não fatais, que resultam em um mínimo de três dias de falta ao trabalho e 160 milhóes de casos novos de doenças profissionais. $\mathrm{O}$ custo total estimado desses acidentes e doenças equivale a $4 \%$ do PIB global. ${ }^{15}$

O Brasil é considerado um recordista mundial de acidentes de trabalho, com três mortes a cada duas horas e três acidentes de trabalho não fatais a cada minuto. Em 2009, foram registrados cerca de 750 mil ATs entre os trabalhadores segurados pelo INSS, sendo que ocorreram 2.851 ATs fatais. Ou seja, em média 31 trabalhadores ao dia não retornaram às atividades de trabalho por invalidez ou morte, o que representa uma morte a cada três horas naquele ano. Porém, esses dados mostram apenas a realidade dos trabalhadores do mercado formal, ou seja, os segurados pelo INSS; calcula-se que metade da população economicamente ativa brasileira esteja na informalidade. ${ }^{18}$

Estudo realizado no estado de Sáo Paulo constatou um total de 3.646 casos fatais de acidentes de trabalho, entre 1997 e 1999, indicando que, a cada ano 1.215 trabalhadores foram vítimas fatais de acidentes 
relacionados ao trabalho, ou seja, a cada dia ocorreram cerca de 3,3 mortes por acidentes laborais. Os homens foram os mais vitimados, em sua maioria adultos na faixa etária entre 20 e 39 anos de idade, e mais de $50 \%$ dos óbitos ocorrem entre indivíduos casados. ${ }^{21}$

No estudo de Miranda et al (2012) ${ }^{18,}$ constatou-se que a maioria dos acidentes atingiu homens jovens e produtivos, participantes ativos na força de trabalho e em atividades de maior grau de risco. A construção civil, seguida pelos transportes, são os ramos de atividade produtiva nos quais ocorre o maior número de ATs fatais. Apontou-se ainda a ocorrência de elevada mortalidade entre trabalhadores com idade até 30 anos e do sexo masculino, e também que o coeficiente de mortalidade é oito vezes maior para os homens em relação às mulheres.

Entre os anos de 2001 e 2007, no Rio grande do Sul, a Previdência Social registrou 997 acidentes do trabalho fatais, incluindo acidentes típicos, de trajeto e de trânsito e doenças do trabalho. A disparidade entre o número de acidentes do trabalho registrados pela Previdência Social e o de acidentes analisados pela SEGUR/RS pode ser explicada pelo elevado percentual de acidentes típicos, ocorridos no âmbito da rua, e os acidentes de trajeto em vias de circulação, geralmente sendo mais graves e com maior número de vítimas fatais, exemplificados pelos acidentes com veículos a motor e atropelamentos. Excluindo-se os acidentes de trajeto, é possível estimar que cerca de $50 \%$ dos acidentes fatais ocorridos com trabalhadores segurados foram investigados pela SEGUR/RS no período. ${ }^{15}$

No estudo de Bortoleto et $\mathrm{al}^{7}$, foi constatado que os ATs acontecem com a mão de obra menos qualificada, com menores salários e menor poder decisório; com um público com ausência ou pouca vinculação sindical e que desconhece os seus direitos enquanto cidadáos e trabalhadores. Em sua maioria, trabalhadores do mercado informal.

Os trabalhadores do mercado informal são aqueles que, além da baixa remuneração, são privados dos benefícios da Previdência Social, não possuem garantia de suporte financeiro em casos de doenças e acidentes e nem aposentadoria remunerada. Outro lado da precarização no trabalho informal é a ausência de sindicalização e a reconhecida negligência dos empregadores quanto às medidas de proteção, segurança e saúde, uma vez que esses trabalhadores encontram-se à margem do controle do Estado. 6,7,22

De acordo com Takahashi et $\mathrm{al}^{22}$, no Brasil a construção civil representa o setor de maior absorção de máo de obra, constituindo-se, portanto, em um setor produtivo importante no cenário econômico. Por outro lado, a magnitude da ocorrência dos acidentes de trabalho e doenças ocupacionais na construção civil, destaca este setor como um dos ramos produtivos mais perigosos, pois esses trabalhadores apresentam estágios mais avançados de precarizaçáo do trabalho que os demais trabalhadores.

Outro agravante na situação dos acidentes de trabalho no Brasil é a sua ocorrência em crianças e adolescentes, situação evidenciada no estudo de Santos e colaboradores $^{23}$ e que se confirma em uma situação de maior gravidade, pois os acidentes ocupacionais são considerados uma forma de violência contra o trabalhador, principalmente o jovem, devido ao fato de poderem acarretar-lhe incapacidades permanentes ou temporárias e até a morte. Tais agravos representam uma importante causa de morbimortalidade entre os indivíduos desse grupo etário.

\section{Acidentes de trabalho: problemas, dificuldades e limitações}

No Brasil, fica evidenciado em muitos estudos que uma das principais lacunas em relação à saúde do trabalhador diz respeito às limitaçóes do sistema de informação (SI) que permitem estimar e acompanhar o real impacto do trabalho sobre a saúde da população brasileira. Essas limitaçôes têm como principal consequência o desconhecimento do impacto do trabalho sobre a saúde e a inexistência de respostas organizadas por parte do SUS em relação à sua prevenção e ao seu controle.

Existem, no Brasil, pelo menos cinco grandes sistemas de informação, implantados e em funcionamento, com dados sobre acidentes e doenças do trabalho, padronizados em todo o território nacional: as Comunicaçóes de Acidentes de Trabalho (CAT), que são informadas ao Instituto Nacional de Seguridade Social (INSS), do Ministério da Previdência Social (MPS) por meio desse sistema operado pela DATAPREV; Sistema de Informaçôes sobre Mortalidade (SIM) com registros das Declarações de Óbito (DO); Sistema de Informaçôes Hospitalares (SIH), gerenciados pelo Ministério da Saúde, com registros de Autorização de Internação Hospitalar (AIH); Sistema de Informação de Agravos de Notificação (Sinan), relativo a acidentes de trabalho, recém-implantado e também gerenciado pelo Ministério da Saúde; e a Relação Anual das Informações Sociais (Rais), gerenciada pelo Ministério do Trabalho e Emprego, com dados sobre movimentação dos empregados com contrato formal de trabalho., ${ }^{9,2}$

A metodologia de vinculação (linkage) de bases de dados se apresenta como alternativa viável para a análise e identificação das ocorrências fatais de acidentes de trabalho, permitindo caracterizá-los e quantificá-los mais adequadamente. A aplicação dessa metodologia apresenta vantagens como baixo custo e contínua periodicidade, uma vez que utiliza os registros administrativos já existentes como os citados anteriormente. ${ }^{21}$ 
Dessa forma, se os sistemas disponíveis no Brasil estivessem integrados, as bases de dados cobririam um universo mais amplo de vítimas de acidentes do trabalho, e representariam relevante contribuição para todos os programas relacionados a essa problemática, auxiliando a precisar quantos trabalhadores se acidentam e morrem no exercício de sua profissáo no país. ${ }^{9,21}$

A partir de 2004, o Ministério da Saúde incorporou ao Sistema Nacional de Notificaçáo de Agravos (SINAN) as doenças e agravos relacionados ao trabalho, que compôem a lista de prioridades no país no sentido de melhorar a qualidade da informaçáo e ampliar a cobertura do registro, inclusive dos trabalhadores do mercado informal. A determinação foi reiterada pela Portaria do Gabinete Ministerial/ Ministério da Saúde no 2472 em 2010. Entre as ocorrências, são notificáveis os acidentes considerados graves e os que ocorreram com exposição a material biológico. Notificaçôes de acidente de trabalho grave são indicadas para os casos fatais, os que resultaram em mutilaçôes e aqueles cujas vítimas são menores de 18 anos. Em 2007, foi iniciada a implantaçáo dessas notificaçôes no SINAN, e incluídos conteúdos relativos à saúde do trabalhador nos programas de treinamento respectivos, em especial nos cursos preparatórios das equipes das unidades sentinelas, isto é, serviços de saúde com a responsabilidade de notificar esses agravos específicos. Foram também elaboradas e adotadas normas de procedimentos, organizadas em protocolos e instruçóes normativas. ${ }^{5,18}$

Dessa forma, o SINAN auxilia significativamente na vigilância de doenças relacionadas ao trabalho, entre elas os ATs fatais, e tem como objetivo coletar dados com maior abrangência que serão analisados e utilizados para desenvolver programas e açóes em saúde do trabalhador no contexto das políticas públicas de saúde. ${ }^{7,18}$

Ainda como proposta para melhorarmos os problemas relacionados ao Sistema de Informação dos eventos e agravos em saúde do trabalhador, Alves e colaboradores $^{24}$ consideram importante investir na capacitação in loco dos profissionais que fazem o atendimento dos eventos e agravos relacionados ao trabalho, ou daqueles lotados nos serviços para onde são encaminhados os atendimentos e não possuem a informação necessária para a qualificação do registro da informação.

De acordo com Alves et $\mathrm{al}^{24}$, problemas com a qualidade da informação não se restringem ao Brasil. $\mathrm{Na}$ África do Sul, a ocorrência de óbitos por causas externas, verificada pelas análises de prontuários e boletins, apresentou um percentual de $28 \%$ de subnotificação de ATs fatais. No Quebec (Canadá), estudos concluíram que somente uma integração entre as fontes de informação pode permitir uma análise mais abrangente desses acidentes.
Portanto, em relação ao perfil de acidentes, mortes e adoecimentos relacionados ao trabalho, são, em geral e sob consenso, destacados dois problemas que ainda carecem de resolução e que, como tais, dificultam a definição de prioridades para o planejamento e a implementação de ações focais: primeiro, a qualidade e a consistência das informaçôes sobre o quadro de saúde dos trabalhadores; segundo, o caráter parcial das informaçóes, cobrindo, sobretudo, o mercado formal de trabalho. ${ }^{9,25}$

Os acidentes de trabalho e doenças relacionadas ao trabalho sáo eventos influenciados por outros aspectos relacionados à situaçáo imediata de trabalho como o maquinário, a tarefa, o meio técnico ou material, e também pela organização e pelas relaçôes de trabalho. No entanto, ainda é preponderante a visão reducionista e tendenciosa de que tais eventos são unicausais, decorrentes em sua maioria de falhas do trabalhador - erro humano, ato inseguro, comportamento fora do padrão ou falhas técnicas materiais, normalmente associadas ao descumprimento de normas e padrōes de segurança. ${ }^{8,9}$

Em relação às teorias sobre a causalidade dos acidentes de trabalho, a primeira enfatiza as mudanças que ocorrem no sistema de produçấo, a falta de conhecimentos, atenção e cuidado, a ausência de cumprimento de regras e, entre outros, desenvolve a cultura de prevenção, considerando as ocorrências de acidentes de trabalho como aprendizado, situando as açôes de prevenção posteriores às ocorrências. A teoria da Ergonomia considera ser a variabilidade presente nas situaçóes reais de trabalho, ou seja, considera que existem diferenças significativas entre o que é prescrito para o desenvolvimento de determinada atividade laboral e o modo como realmente é feita. No dia a dia, os trabalhadores se veem obrigados a tomar certas decisóes e executar certas medidas para o funcionamento da produçáo que não estão prescritas nas normas e procedimentos, e a análise dos acidentes deve considerar essa variabilidade entre o que é prescrito e o que realmente é feito. Nessa teoria também ganharam corpo as explicaçôes da confiabilidade humana em sistemas considerados seguros, como os de ordem técnica, eliminando as explicaçóes que consideram os trabalhadores como únicos agentes da causa dos acidentes. ${ }^{9}$

A teoria proposta por Almeida e Binder $(2005)^{26}$ analisa o acidente de trabalho a partir do método Árvore de Causas, mostrando que o mesmo permite identificar as várias situaçôes de trabalho e comparar a situaçáo real do trabalho sem acidente e a situação real do trabalho com acidente, cuja vantagem está em identificar os vários contextos e circunstâncias do trabalho, sendo mais favorável às medidas de segurança e prevenção.

O estudo de Gonçalves e Dias ${ }^{6}$ evidenciou que quando a compreensão dos acidentes de trabalho rompe com 
o enfoque clássico que culpa os trabalhadores acidentados por seus atos inseguros, outros fatores que revelam problemas na própria organização e que são precursores primários desses acidentes podem ser identificados, como a disfunção organizacional.

Como proposta de análise que permita uma melhor compreensão dos determinantes e condicionantes do acidente de trabalho, a proposta do modelo de análise e prevenção de acidentes (MAPA) estimula o desenvolvimento de reflexóes sobre a criação ou introdução de novos perigos e riscos, e a busca de aperfeiçoamentos, seja dos marcos regulatórios adotados, seja das escolhas políticas relativas aos modelos de crescimento ou desenvolvimento econômico assumidos no território. Em termos práticos, isso significa que em toda análise de acidente as equipes envolvidas devem explorar a possibilidade da existência de escolhas de política econômica ou lacunas da legislação (econômica, importação de máquinas e equipamentos, gestão de segurança, resposta de emergência etc) que tenham contribuído para a criação do perigo/risco, persistência da situação de exposiçãa e/ ou instalação de consequências do ocorrido. ${ }^{8}$

O modelo de análise estimula ao final a elaboração de uma síntese explicativa do processo causal, em busca dos determinantes do acidente - as causas latentes ou causas das causas - normalmente situadas em falhas gerenciais, práticas de divisão de trabalho, gestão de manutenção, logística, gestão de atrasos de produção, gestão de projetos, falhas na gestấo de pessoal, materiais, adequaçáo de demandas a recursos existentes, de perdas de oportunidade de aprendizagem com episódios anteriores que deveriam ter sido detectados e interpretados como avisos de que o acidente se aproximava, entre outras condiçóes organizacionais. ${ }^{8}$

Dessa forma, novas concepçóes acerca dos acidentes estáo ganhando força por parte de estudiosos do tema e, em consequência, novos modelos de análise vêm sendo desenvolvidos, buscando identificar na complexidade desses eventos os fatores sociotécnicos que os desencadeiam e, simultaneamente, as condiçóes preexistentes no trabalho sem as quais os acidentes não ocorreriam. ${ }^{8,22}$

Para que este novo conteúdo paradigmático estabeleça a ruptura desejada, é preciso que ele seja compartilhado com os trabalhadores, com o corpo técnico das empresas, com as instâncias públicas de regulação e com as entidades sindicais, transformando-se em fundamentos mais efetivos na construçáo de consensos e compromissos destes diferentes atores sociais na construção de uma efetiva política pública de prevenção dos acidentes de trabalho. ${ }^{8,22}$

\section{Acidentes de trabalho: consequências e sequelas}

$\mathrm{O}$ acidente de trabalho proporciona um grande impacto na vida do indivíduo. O trabalhador acidentado, além de passar pelo sofrimento relacionado à lesão física, ou até mesmo perder da vida, pode estar sujeito a danos psicológicos muitas vezes irreversíveis. Afinal, tais acidentes podem ocasionar sequelas no indivíduo, e torna-lo inapto para exercer suas atividades laborais de forma provisória ou permanente. ${ }^{27}$

Além da possibilidade de causar limitaçóes e incapacidades, a doença ou o acidente de trabalho pode levar ao comprometimento de atividades cotidianas do trabalhador, incluindo implicaçóes para o desenvolvimento de suas rotinas domésticas e de atividades de lazer. Em função disso, pode gerar nos indivíduos afetados sentimentos de frustraçáo e inutilidade. Esses sentimentos na maioria dos casos são acompanhados pela dor, insônia, oscilação do humor, baixa autoestima, depressão, ansiedade, desvalorizaçáo profissional, entre outros que muitas vezes são sintomas de transtornos mentais que se tornam uma das principais sequelas no trabalhador vitimado. ${ }^{29}$

Outros problemas apontados pelos estudiosos das áreas de saúde e ciências humanas sobre a situação de risco no ambiente de trabalho são os sentimentos de medo e a culpabilização pelo acidente. Esses sentimentos acabam fragilizando psicologicamente os profissionais que vivem em uma situação de risco nos seus ambientes de trabalho, o que ocasiona, por sua vez, a não notificação dos acidentes. ${ }^{6,29}$

$\mathrm{Na}$ realidade dos ambientes de trabalho no Brasil a aplicação das açôes prevencionistas contidas nas normas e leis ainda é bastante limitada e permeada de lacunas. Os óbitos e mutilaçóes por acidentes continuam acontecendo, causando grandes prejuízos pessoais, sociais e econômicos às famílias, elevados custos para o Estado, tanto de forma direta, pelos gastos assistenciais e previdenciários, quanto de forma indireta, pela perda de tudo o que aquele cidadão poderia contribuir com seu labor e do que foi investido na sua formação pessoal e profissional. ${ }^{15}$

É importante salientar que o ambiente de trabalho é um espaço onde são vivenciadas experiências subjetivas e coletivas. Nesse sentido, quanto maior o sentimento de pertencimento do trabalhador a um coletivo, maior será a preocupação em mantê-lo protegido dos riscos. ${ }^{29}$

No entanto, mesmo estando cientes das situações de risco para os acidentes de trabalho, os trabalhadores se submetem a elas, provavelmente pelo contexto social atual no qual estar empregado, mesmo em precárias condiçôes, já é uma situação de privilégio. O medo da perda do emprego assume extrema relevância, principalmente no mundo do trabalho atual, frente à difícil situação de se conseguir outro emprego, sendo que a necessidade de mantê-lo traz consigo a impossibilidade de propor mudanças nesse contexto e faz com que os trabalhadores se submetam a condiçóes de trabalho, muitas vezes, incompatíveis com a saúde. ${ }^{6,28}$ 
Esse fenômeno de naturalização e aceitação dos riscos pelo trabalhador tem sido discutido e estudado por muitos pesquisadores principalmente a partir de estudos que analisam as perspectivas dos trabalhadores. $\mathrm{O}$ estudo de Takahashi e colaboradores ${ }^{22}$ detectou conteúdos diferenciados nas falas dos trabalhadores em relação aos EPIs: a referência ao uso propriamente dito dos equipamentos, ao desconforto que eles provocam no trabalhador, e como muitas vezes eles atrapalham na condução das tarefas, principalmente diante da intensificação do trabalho e das exigências de perfeição e cumprimento de prazos, ou seja, da pressão por qualidade e produtividade, características fortemente marcadas no mercado de trabalho capitalista competitivo. Aos efeitos psicossociais desses constrangimentos, aliam-se a fragilidade dos vínculos que tangenciam as atitudes de adaptação e submissão; os conteúdos de causas intersubjetivas que expressam os modos de regulação dos operários diante da necessidade de lidar com os riscos.

No estudo de Gonçalves e Dias ${ }^{6}$, o relato de grande parte dos trabalhadores apontou como explicaçóes para os acidentes o ritmo de trabalho, os problemas de ordem organizacional do trabalho e os fatores emocionais relacionados com o próprio trabalho (estresse, ruído, problemas econômicos), desvinculados das ideias clássicas sobre a culpabilidade da vítima e a naturalização do acidente.

Os autores justificam ainda essa percepção como um sistema defensivo partilhado entre todas as categorias profissionais da construção civil, cuja eficácia simbólica é assegurada pela participação coletiva. Por se tratar de uma ideologia defensiva de profissão, torna-se incontestável seu valor funcional, uma vez que as atitudes de negação do risco representam uma ocultação da vivência cotidiana do medo, que se encontra contida por mecanismos de defesa, e que têm a função psicológica de neutralizar essa emoção para preservar a saúde mental dos trabalhadores. Esses mecanismos de defesa são de caráter coletivo, e sua eficácia simbólica depende da aceitaçáo e participação de todos. Caso contrário, se o medo aparecesse a toda hora durante o trabalho, os trabalhadores certamente não conseguiriam continuar em suas tarefas por muito mais tempo. ${ }^{22}$

Nessa perspectiva, quando a compreensão dos acidentes de trabalho rompe com o enfoque clássico que culpa os trabalhadores acidentados por seus atos inseguros, outros fatores podem ser identificados que evidenciam problemas na própria organização e que são precursores primários desses acidentes. ${ }^{6}$

Acidentes de trabalho: o passado, o presente e o futuro.

Numa perspectiva histórica, foram inegáveis os benefícios que a Revolução Industrial trouxe às sociedades modernas. Contudo, esse "novo" período acarretou também alguns efeitos adversos, notavelmente no que se refere à "produção" de acidentes. As novas formas de organização do trabalho, fruto da Revolução Industrial, são, em grande medida, responsáveis pela sinistralidade laboral massiva e sistemática que caracterizou o mundo do trabalho nos últimos dois séculos. ${ }^{30}$

No decorrer da história, movimentos sociais e lutas sindicais contribuíram na construção de legislaçôes que foram modelando as relaçôes de trabalho. Os conceitos de cidadania e de respeito à dignidade do trabalhador são modernos, surgiram a partir do Iluminismo e de um longo processo de construção social em que todos os seres humanos possuem direitos fundamentais, entre eles a vida e a integridade física. ${ }^{15}$

No Brasil, fazem parte desse arcabouço jurídico de proteçáo à saúde do trabalhador a constituição de 1988, as Normas Regulamentadoras (NR), a Portaria no 3.214 de 8 de junho de 1978, do Ministério do Trabalho e Emprego (MTE), que regulamentam o Capítulo V da Consolidação das Leis do Trabalho (CLT) ${ }^{15}$. Além das Portarias 777, de 28 de Abril de 2004, que regulamentaram a notificação compulsória de acidentes e doenças relacionados ao trabalho; GM/MS no 3.252, de 22 de dezembro de 2009, que aprova as diretrizes para execução e financiamento das açôes de Vigilância em Saúde pela Uniáo, estados, Distrito Federal e municípios e a GM/MS no 2.472, de 31 de agosto de 2010, que unifica a relação de doenças, agravos e eventos em saúde pública de notificação compulsória em todo o território nacional. ${ }^{2,4,14,16}$

Em que pese o arcabouço jurídico protetor existente, a ocorrência de acidentes de trabalho com mortes e incapacidades laborativas revelam a permanente necessidade de prevençáo. Essa realidade nos desafia a refletir a respeito dos fatores políticos, econômicos e sociais e seus determinismos que repercutem no mundo do trabalho, além de suas implicaçôes na vida e saúde do trabalhador. ${ }^{15}$

No entanto, a atenção à saúde do trabalhador no Brasil apresenta problemas graves em diversas áreas, tais como: assistência à saúde inadequada, falta de fiscalização, subnotificacão dos casos, ausência de sistematização dos dados coletados, dificuldades no reconhecimento do nexo entre trabalho e doença e no cumprimento da legislação, pouca ênfase na promoção/prevenção, entre outros.

Destaca-se ainda a importância da construção de sistemas ampliados e integrados de informaçóes, entendendo essa ação como fundamental para promover mudanças nas políticas de saúde e, consequentemente, gerar melhorias na segurança do trabalhador. Atualmente, o problema do AT no Brasil assume proporções bem maiores do que as estatísticas permitem vislumbrar?

Miranda et $\mathrm{al}^{18}$ propóem que as açóes preventivas em saúde do trabalhador ultrapassem o espaço físico das 
empresas devido à nova realidade do mundo de trabalho. Na perspectiva de prevenção do AT, é necessário investir em educação, além da educação no trânsito, por meio de políticas públicas com campanhas em mídias e a revitalização do transporte coletivo, a fim de evitar os ATs e suas consequências. Além disso, deve-se estimular e apoiar pesquisas que avaliem o comportamento no trânsito, riscos de acidentes devido às condiçóes do veículo e novas abordagens de sensibilização e estímulo ao uso dos equipamentos de proteção individual.

$\mathrm{O}$ estudo de Galdino et $\mathrm{a}^{5}$ evidenciou que as dificuldades na implantação das açóes em saúde do trabalhador são semelhantes àquelas descritas para o SUS, com o agravante das especificidades desse campo. Além da falta de articulação entre as instituiçôes responsáveis por açôes em saúde do trabalhador, como os Ministérios do Trabalho e Emprego, da Saúde e da Previdência Social, através da ausência de compartilhamento de dados úteis para a vigilância da saúde do trabalhador, especialmente os da notificaçẫo, como os provenientes das inspeçôes de ambientes de trabalho e dos sistemas de benefícios. Outro problema seria a desarticulação entre a saúde do trabalhador e as demais vigilâncias desenvolvidas pelo próprio SUS, além dos limites da compreensão do trabalho como determinante da saúde pelos profissionais da saúde.

Dessa forma, fica latente a necessidade e importância da implantação e consolidação efetivas dos CEREST no Brasil, no sentido de avançar no processo de vigilância na Saúde do trabalhador através de açóes de incentivo à configuração de uma rede com unidades notificantes que devem refletir nas açôes de estruturaçáo das redes sentinelas e na capacitaçáo dos seus profissionais. Com isso, favorecem a consolidação das estratégias de implantação do SINAN e a continuidade das atividades desenvolvidas em busca da superaçáo da grande subnotificação de acidentes de trabalho'.

Enfim, o SUS tem o compromisso de continuamente trabalhar para a melhoria da situaçáo de saúde da população brasileira, partindo da concepção que o trabalho é um dos condicionantes mais estruturantes para que este objetivo seja atingido, o que passa pela articulação e fortalecimento das diversas açôes governamentais envolvidas, pelo aprimoramento da participaçáo social na implementação dessas açóes, pelo fortalecimento do campo da saúde do trabalhador e pela própria concretização do SUS, uma conquista histórica da sociedade brasileira $^{25}$.

\section{Considerações finais}

Acredita-se que o entendimento dos contextos no qual se apresentam os cenários dos acidentes de trabalho no Brasil, os riscos ocupacionais aos quais estáo expostos os trabalhadores, os fatores e característica que estáo inseridos nesse contexto, os limites e dificuldades no processo de vigilância em saúde e as possibilidades e estratégias de avanços nessa área - irão subsidiar o processo de planejamento, organização e intervençóes da enfermagem do trabalho no referido campo de atuação.

Portanto, conhecer as dificuldades, limitaçóes e consequências que os acidentes de trabalho ocasionam na vida dos trabalhadores, constitui aspecto essencial para a atuação da enfermagem e de outros profissionais que lidam direta e indiretamente no cuidado a saúde do trabalhador. Tal conhecimento propicia a tomada de decisóes, no intuito de minimizar os riscos ocupacionais e, ao mesmo tempo, colaborar para a promoçáo de ambientes de trabalho saudáveis e para a manutenção da capacidade produtiva dos indivíduos.

Finalmente, estudos como este se tornam necessários, visto que, com uma descrição precisa sobre os contextos dos acidentes de trabalho e dos trabalhadores vitimados, torna-se possível compreender com mais profundidade esse fenômeno no sentido de ampliar o conhecimento nessa área e subsidiar outras pesquisas, além de contribuir no desenvolvimento de políticas públicas específicas e eficazes para a promoção da saúde dos trabalhadores.

\section{Referências}

1. Aragón A, Partanen T, Felknor S, Corriols M. Social determinants of workers' health in Central America. Int J Occup Environ Health. 2011;17(3):230-7.

2. Brasil. Ministério da Previdência Social. Lei no 8.213 , de 24 de julho de 1991. Dispóe sobre os Planos de Benefícios da Previdência Social e dá outras providências. DOU, Brasília, 14 ago 1991.

3. Brasil. Ministério da Saúde. Lei no 8080, de 1990. Lei Orgânica de Saúde. DOU, Brasília, 20 set. 1990.

4. Brasil. Ministério da Saúde. Rede nacional de atenção integral à saúde do trabalhador. Manual de Gestão e Gerenciamento. 1a ed. Brasília, 2006.

5. Galdino A, Santana V S, Ferrite S. Os centros de referência em saúde do trabalhador e a notificação de acidentes de trabalho no Brasil. Cad Saúde Públ. 2012;28(1):145-59.

6. Gonçalves CGO, Dias A. Três anos de acidentes do trabalho em uma metalúrgica: caminhos para seu entendimento. Ciênc Saúde Colet. 2011;16(2):635-646.

7. Bortoleto MSS, Nunes EFPA, Haddad MCL, Reis GAX. Acidentes de trabalho em um pronto atendimento do Sistema único de saúde. Espaç Saúde. 2011;13(1):91-97.

8. Almeida IM, Vilela RAG. Modelo de análise e prevenção de acidente de trabalho - MAPA. Piracicaba: CEREST, 2010. 
9. Lourenço EAS. Agravos à saúde dos trabalhadores no Brasil: alguns nós críticos. Pegada. 2011;12(1):3-33.

10. Hinds PS, Chaves DE, Cypress SM. Context as a source of meaning and understanding. Qual Health Res. 1992;2(1):61-74

11. Rother ET. Revisão sistemática $X$ revisão narrativa. Acta Paulista de Enfermagem [periódico na Internet]. 2007 abr./jun. 2007. [acesso em \{inserir data de acesso\}]; 20(2). Disponível em: http://www.scielo.br/scielo. php?pid=S0103-21002007000200001\&script=sci_arttext

12. Organizaçáo Internacional do Trabalho (OIT). Resolução sobre as estatísticas das lesóes profissionais devidas a acidentes do trabalho. $16^{\circ}$ Conferência Internacional de Estatísticas do Trabalho. 1998.

13. Silva TR, Rocha SA, Ayres JA, Juliani CM. Acidente com material perfurocortante entre profissionais de enfermagem de um hospital universitário. Rev. Gaúcha Enferm. 2010;31(4):615-22.

14. Ministério da Saúde (BR). Notificação de acidentes do trabalho fatais, graves e com crianças e adolescentes. Brasília: Editora do Ministério da Saúde, 2006.

15. Ministério do Trabalho e Emprego (Brasil) Análises de acidentes do trabalho fatais no Rio Grande do Sul: a experiência da Seçấo de Segurança e Saúde do Trabalhador SEGUR. Porto Alegre: SEGUR, 2008.

16. Ministério da Saúde (BR). Secretaria de Atenção à Saúde. Departamento de Ações Programáticas Estratégicas. Exposição a materiais biológicos. Brasília: Ministério da Saúde; 2006.

17. Amorim CR, Araújo EM, Araújo TM, Oliveira NF. Acidentes de acidentes de trabalho com mototaxistas. Rev Bras Epidemiol. 2012;15(1): 25-37

18. Miranda FMD, Scussiato LA, Kirchhof ALC, Cruz EDA, Sarquis LMM. Caracterização das vítimas e dos acidentes de trabalho fatais. Rev Gaúcha Enferm. 2012;33(2):45-51.

19. Sêcco IAO, Robazzi MLCC, Shimizu DS, Rúbio MMS. Acidentes de trabalho típicos envolvendo trabalhadores de hospital Universitário da regiáo sul do Brasil: epidemiologia e prevenção. Rev Latino-am Enferm. 2008;16(5).

20. Almeida PCA, Barbosa-Branco A. Acidentes de trabalho no Brasil: prevalência, duração e despesa previdenciária dos auxílios-doença. Rev Bras Saúde Ocup. 2011;136(124):195-207

21. Waldvogel BC, Freitas RMV, Teixeira MLP. A fundação Seade e os estudos sobre mortalidade por acidentes de trabalho no estado de São Paulo. In: Brasil. Ministro do Trabalho e Emprego. Saúde e segurança no trabalho no Brasil: aspectos institucionais, sistemas de informação e indicadores2011. Brasília: IPEA, 362-75.

22. Takahashi MABC, Silva RC, Lacorte LEC, Ceverny GCO, Vilela RAG. Precarização do Trabalho e Risco de Acidentes na construçáo civil: um estudo com base na Análise Coletiva do Trabalho (ACT). Saúde Soc. 2012;21(4):976-988.

23. Santos MEA, Mauro MYC, Brito CG, Machado DC. Trabalho precoce e acidentes ocupacionais. Esc Anna Nery Rev Enferm. 2009;13(4):824-32

24. Alves MMM, Nomellini PF, Pranchevicius MCS. Mortalidade por acidente de trabalho no Estado do Tocantins. Epidemiol. Serv Saúde. 2013;22(2):243-254.

25. Ministério do Trabalho e Emprego (BR). Saúde e segurança no trabalho no Brasil: aspectos institucionais, sistemas de informação e indicadores. Brasília: Ipea, 2011

26. Binder MCP, Almeida IM. Acidentes do Trabalho: Acaso ou descaso? In: Mendes R. (Org.). Patologia do Trabalho: atualizada e ampliada. São Paulo: Athneu, 2005, p.769-808.

27. Motta PT, Carvalho RLR, Duarte MEL, Rocha AM. Análise dos acidentes de trabalho do setor de atividade econômica comércio no município de Belo Horizonte. Rev Min Enferm. 2011;15(3):427-33.

28. Rodrigues BC, Moreira CCC, Triana TA, Rabelo JF, Higarashi IH. Limitaçóes e consequências na vida do trabalhador ocasionadas por doenças relacionadas ao trabalho. Rev Rene. 2013;14(2):448-57.

29. Silva EJ, Lima MG, Marziale MHP. O conceito de risco e os seus efeitos simbólicos nos acidentes com instrumentos perfurocortantes. Rev Bras Enferm. 2012;65(5):809-14.

30. Areosa J, Dwyer T. Acidentes de trabalho: uma abordagem sociológica. Configuraçôes [periódico na Internet], 2010. [acesso em 18 Fevereiro 2012]. Disponível em: http://configuracoes.revues.org/213 